\title{
Effects of extraction method on dry pulp yield and morphological properties of pineapple leaf fibre
}

\author{
Dayangku Intan Munthoub, Wan Aizan Wan Abdul Rahman, Lew Jin Hau, Rohah A. Majid, \\ Lai Jau Choy *
}

Biopolymer Research Group, School of Chemical and Energy Engineering, Faculty of Engineering, Universiti Teknologi Malaysia, UTM Johor Bahru, 81310, Johor, Malaysia

* Corresponding author: jclai@utm.my

\section{Article history}

Received 6 January 2020

Revised 13 February2020

Accepted 19 March 2020

Published Online 15 June 2020

\section{Graphical abstract}

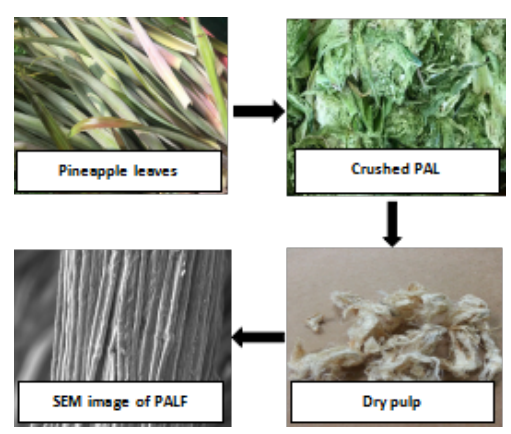

\section{Abstract}

Pineapple leaves (PALs) are useful agro wastes which have the potentials to be used as an alternative source of non-wood natural fiber. In this study, different extraction methods had been investigated to identify the most feasible pineapple leaf fiber (PALF) extraction method, based on the dry pulp yield and the PALF morphology. The manual retting using a ceramic scrapper led to low yield of around $1.8 \%$ (wt.), while water retting for $21 \mathrm{~d}$ led to about $6.0 \%$ (wt.) yield of dark greenish dry pulp. Both methods resulted in PALFs which still contained with non-cellulosic residues, as verified by scanning electron microscopic (SEM) imaging. The chemical extraction of PALF using various $\mathrm{NaOH}$ solution concentrations (i.e. 1 to $20 \%$ (wt.)) gave different yields. Based on the SEM images, clean and smooth surfaces of fibrils were observed when the $\mathrm{NaOH}$ solution concentrations applied at or higher than $6 \%$ (wt.), implying that all impurities including lignin and wax had been completely removed. The mechanical-chemical extraction method produced significantly more dry pulp compared to the chemical extraction method at the same $\mathrm{NaOH}$ solution concentration. This is attributed to the fact that the crushed PAL has a larger surface area, thus providing more reaction possibilities with $\mathrm{NaOH}$ solution. Finally, it was found that the crushed PAL that cooked at $90{ }^{\circ} \mathrm{C}$ needed at least 90 min of cooking time to obtain satisfying whitish dry pulp.

Keywords: Pineapple leaf, fibre extraction, extraction methods, dry pulp yield, fiber morphology

\section{INTRODUCTION}

Increasing global industrialization has led to significant consumption of paper especially for the purpose of packaging, which accounts for over $41 \%$ of paper usage globally (Beckline et al., 2016). According to the pulp and paper capacities survey 2013 - 2018 by the Food and Agriculture Organization of the United Nations (FAO, 2014), the global paper consumption will increase to 500 million tons in year 2025 which corresponds to an annual paper consumption growth of 1.6 $\%$. The intensive paper consumption leads to significant depletion in natural resources especially wood due to rapid deforestation. Therefore, much efforts have been invested to study different non-wood alternatives as potential candidates for paper production, which include palm oil empty fruit bunch (Rodríguez et al., 2014; Kim et al., 2014), bagasse (Rezayati-Charani et al., 2006), wheat-straw (Hedjazi et al., 2009), sugarcane straw (Saad et al., 2008), rice-straw (Rodríguez et al., 2008), napier (Rodríguez et al., 2008; Haameem et al., 2016), kenaf (Low et al., 2018), tea waste/kapok (Majid et al., 2018), tree pruning waste (Low et al., 2019) and reeds (Feng and Alén, 2001). One of the potential replacements of wood in paper pulp production is pineapple leaf fiber (PALF), which is abundantly available in Malaysia (Daud et al., 2013; Yusof et al., 2012). Several researches have been reported to utilize pineapple biomass in Malaysia especially pineapple leaves including PALF/polypropylene (PP) composites (Arib et al., 2006), PALF/glass vinyl ester (VE) hybrid biocomposites (Zin et al., 2019), PALF/polyester composites (Senthilkumar et al., 2019), silane treated keaf/PALF phenolic hybrid biocomposites (Asim et al., 2018), scratch resistance epoxy composites from PALF, napier and hemp fibres as filler (Ridzuan et al., 2019), sound adsorption (Putra et al., 2018) and soil cover (Sarah et al., 2018).

Pineapple leaf (PAL) serves as an attractive option to pulp making as pineapple plant can produce up to $1.5 \mathrm{~kg}$ of leaves per plant that left in the field after cultivation (Sibaly and Jeetah, 2017). Furthermore, the PALF possesses high cellulose content (66.2\%) and low lignin content $(4.2 \%)$ which offer good mechanical properties to handle the potential abrasion and tear as packaging material (Mohamed et al., 2009; Daud et al., 2013). Cellulose is a long branchless glucose polymer that can influence the thermal degradation properties of the fibre (Lai et al., 2013) and the strength of the paper (Laftah and Abdul Rahaman, 2015), resulting PALF to has immense potential as reinforcement and can be utilized as the alternative source of fiber for composites and pulp industry.

With the positive reports from several studies, an effective fiber extraction method must be established to enhance the feasibility of PAL usage as a non-wood alternative for pulp production (Daud et al., 2013; Yusof et al., 2012). The conventional extraction method often falls into three categories, namely mechanical method, chemical method and mechanical-chemical method. Sarah et al. (2018) reported that the fibers extracted using a mechanical-chemical method had low lignin content and high crystallinity when compared to the "roller and bladder" mechanical system and chemical extraction with sodium hydroxide $(\mathrm{NaOH})$ solution and acetone. Sarah et al. (2018) used immersion technique when dealing with chemical extraction method as the PALF was soaked in the solution for $24 \mathrm{~h}$ without any addition of heat during the process. 
This paper was reported on the comparison between the effectiveness of the mechanical, chemical and chemical-mechanical methods in extracting the PALF from the PAL. The effects of heating in speeding up the process were also investigated and discussed.

\section{EXPERIMENTAL}

\section{Materials}

The pineapple leaves (PALs) of Josapine variant were collected from the Malaysian Pineapple Board (MPIB) plantation in Alor Bukit, Pekan Nanas, Johor, Malaysia. An industrial grade of sodium hydroxide $(\mathrm{NaOH})$ flake was purchased from PT Asahimas Chemical. The distilled water was used in solution preparation.

\section{Extraction Methods}

\section{Combing method (Manual Retting)}

Pineapple leaves (PALs) were cleaned using tap water to remove the dirt and other residues. The cleaned PALs were combed with a ceramic scraper to extract the PALF by removing the non-fibrous components from the leaves. The fibers obtained were washed under running tap water to remove the remaining dirt residues. The extracted fibers were then sun-dried for few days until constant weights were achieved. Weights of the extracted fibers, PALFs were recorded.

\section{Water retting method}

The clean PALs were crushed using a fabricated sugarcane crusher machine. The crushed PALs were then soaked in water using the solid/liquid ratio of $1: 15$ for $(3,7,10,14,17$ and 21$) \mathrm{d}$. The retted fibers were then cleaned under running tap water and oven-dried at $60{ }^{\circ} \mathrm{C}$ for $24 \mathrm{~h}$. Weights of the extracted PALFs from each soaking time were recorded.

\section{Chemical extraction method}

Sodium hydroxide $(\mathrm{NaOH})$ solution was used as a medium to extract PALF from the fresh PALs. The $\mathrm{NaOH}$ solutions were prepared at different concentrations between (1 to 20) \% (wt.) by dissolving the $\mathrm{NaOH}$ flakes in distilled water. The clean PALs were cut into approximately $5 \mathrm{~cm}$ in length prior to soaking in the $\mathrm{NaOH}$ solution by using the solid/liquid ratio of $1: 15$ for $24 \mathrm{~h}$ at room temperature $\left(25^{\circ} \mathrm{C}\right)$. After $24 \mathrm{~h}$, the treated PALs were washed under running tap water until the fibers became clear yellowish in colour. The cleaned fibers were then oven-dried overnight at $60{ }^{\circ} \mathrm{C}$. Weight of the dried PALF was weighed and recorded.

\section{Mechanical-chemical extraction method}

The mechanical-chemical extraction method followed similar routes as in the chemical extraction method. The $\mathrm{NaOH}$ solution concentrations of $(1,3,5,7,9$ and 11) \% (wt.) were used. The PALs were crushed with a crusher prior to undergoing the alkali $(\mathrm{NaOH}$ solution) treatment. The crushed PALs were then cooked in the $\mathrm{NaOH}$ solutions at $90^{\circ} \mathrm{C}$ with different cooking times as described previously in the chemical extraction method.

In cooking time experiments, the clean PALs were added to $\mathrm{NaOH}$ solution with different concentrations (i.e. 1, 3, 5, 7, 9 and 11) \% (wt.) using the solid/liquid ratio of 1:15. The mixtures were then heated at 90 ${ }^{\circ} \mathrm{C}$. The cooking times were varied at $(30,60,90,120$ and 180) min for each experiment. Once completed, the PALs were cleaned and washed under running tap water until they were free of residues. The fibers were oven-dried overnight at $60{ }^{\circ} \mathrm{C}$. Weights of the dried PALFs were recorded.

\section{Dry pulp yield}

The dry pulp yield was calculated according to Eq. (1)

$$
\text { Dry Pulp Yield }(\%)=(B / A) X 100
$$

where A is the initial mass of PAL used in the extraction process $(\mathrm{g})$ and $\mathrm{B}$ is the mass of the PALF obtained from the extraction process $(\mathrm{g})$.

\section{PALF morphology}

The PALF morphology and fiber arrangement were determined by using a scanning electron microscope (SEM) model JEOL JSMIT300LV (USA). Prior to the scanning, the samples were sputteringcoated with $10 \mathrm{~nm}$ platinum under vacuum. The SEM images of the samples were taken at different magnifications. The visual images were obtained using a conventional digital camera model Samsung N7100 (Korea).

\section{RESULTS AND DISCUSSION}

\section{Combing method (Manual Retting)}

A whitish PALF obtained from the manual retting method is shown in Fig. 1. The average dry pulp yield from this method was calculated to be $1.8 \%$ (wt.). In average, the process to obtain $0.7 \mathrm{~g}$ of PALF from a single leaf weighed around $40 \mathrm{~g}$ took almost $20 \mathrm{~min}$. The SEM image in Fig. 1(b) shows the residue of non-cellulosic substances on the surface of the fiber. Since the fibers were manually extracted using a scrapper, the quality (i.e. trace of impurities) and the amount of fibre yield (loss of fibres) depended on the skill of the workers. Hence, the combing method was is not a plausible fiber extraction method, especially for big scale production.

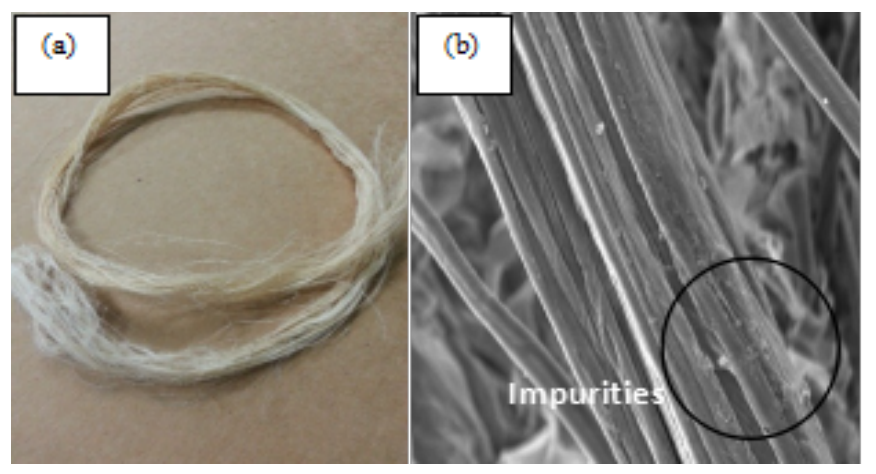

Fig. 1 (a) Visual and (b) SEM (1500X magnification) images of the manually retted PALF.

\section{Water retting method}

The image of water retted PALF and its SEM images are shown in Fig. 2, while the dry pulp yield of PALs is presented in Fig. 3. It could be observed that the dry pulp yield decreased with increasing number of immersion time, where the dry pulp obtained in $21 \mathrm{~d}$ was between (6.0 to 6.6 ) \% (wt.). The trend was due to the fact that more noncellulosic substances were softened and washed away as the day of immersion increased. These values were significantly higher than that of the manual retting method. As compared to the manual retting, this extraction method did not require manual labour to remove the residues or impurities from the PALF. However, the SEM images show that some residues still remained on the surface of the fibers. The dark greenish colour of the PALF as shown in Fig. 2(a) was thought to correspond to the presence of residues in the fiber (Wang et al., 2016). Hence, the water retting method was also less effective.

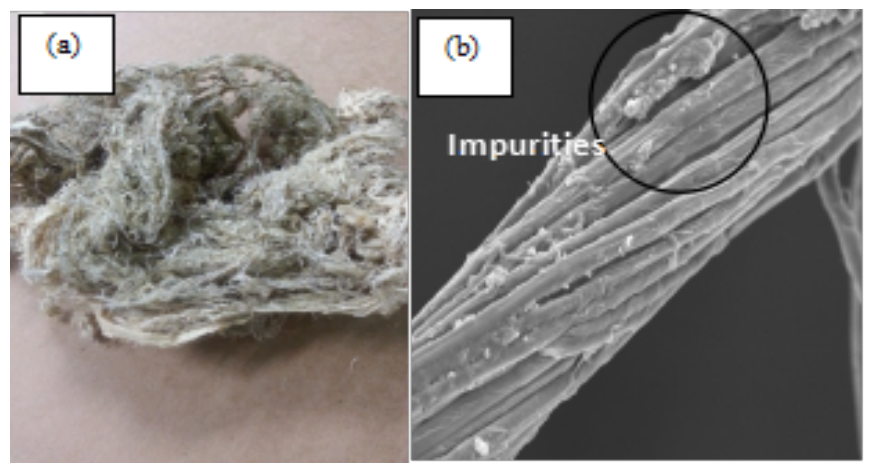

Fig. 2 (a) Visual and (b) SEM (1500X magnification) images of water retted PALF after $21 \mathrm{~d}$ of immersion. 


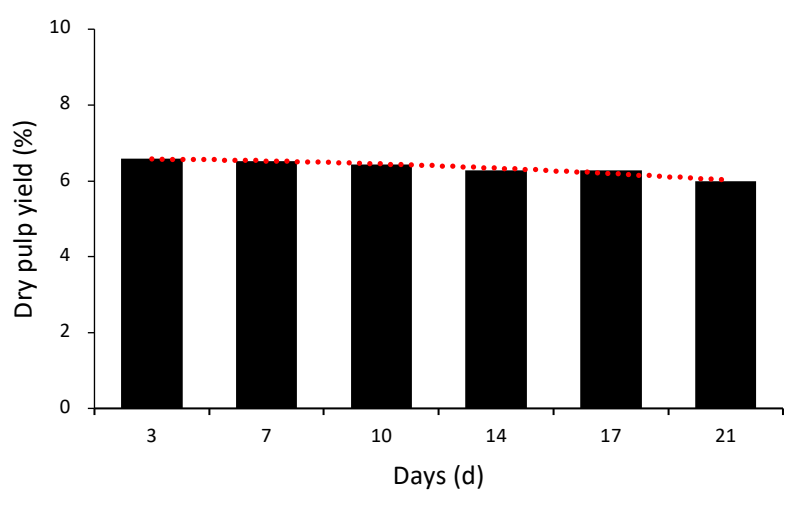

Fig. 3 Effect of immersion time on the dry pulp yield of water retting method.

\section{Chemical extraction method}

A sample of PALF extracted using $\mathrm{NaOH}$ solution is shown in Fig. 4, while the dry pulp yield of the chemically treated PAL is shown in Fig. 5. The extracted PALF was seen to be whitish in colour, signifying a complete removal of lignin. During the process, the $\mathrm{NaOH}$ has disrupted the lignin-carbohydrate linkages that subsequently introduced partial removal of hemicellulose and tfacilitated the lignin removal (Jahan and Pourali, 2019). Fig. 5 clearly shows that the dry pulp yield decreased with increasing $\mathrm{NaOH}$ solution concentrations. However, after $7 \%$ (wt.) $\mathrm{NaOH}$ solution cencentration, the dry pulp yield was constant at around $3 \%$ (wt.), which was consistent with other studies (Mohamed et al., 2009; Daud et al., 2013; Laftah and Abdul Rahaman, 2015).

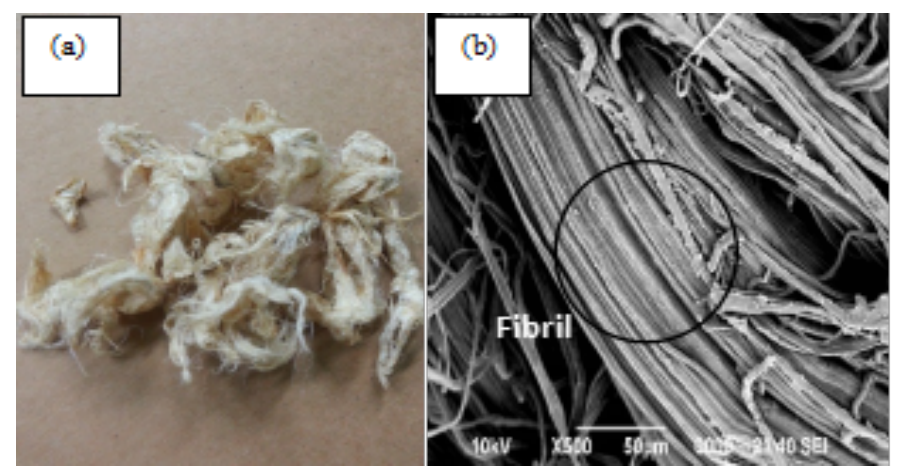

Fig. 4 (a) Visual and (b) SEM (500X magnification) images of the chemically extracted PALF using $15 \%$ (wt.) $\mathrm{NaOH}$ solution concentration.

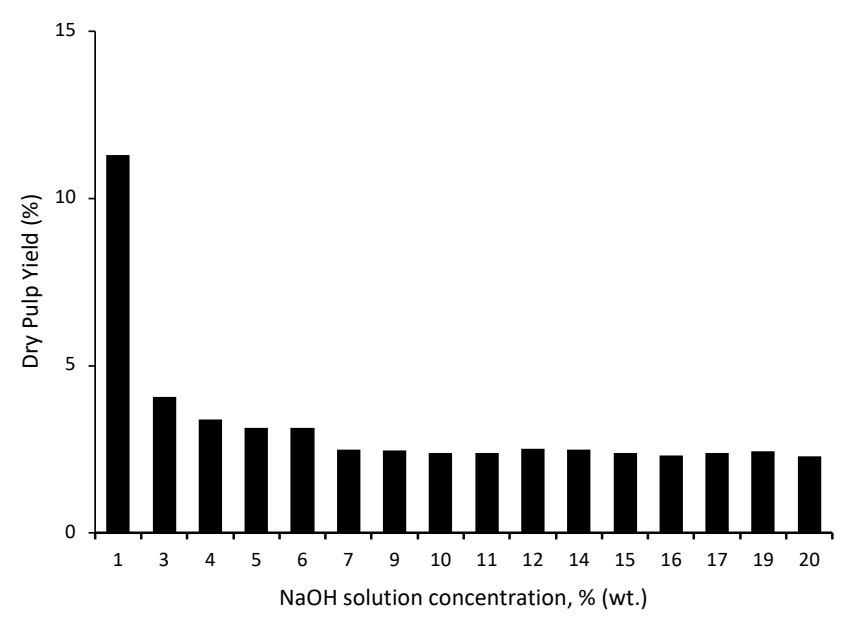

Fig.5 Effect of $\mathrm{NaOH}$ solution concentrations on the dry pulp yield of the chemical extraction method.
Fig. 6 shows the SEM images of the PALF extracted using six different $\mathrm{NaOH}$ solution concentrations. It is obviously shown in Figs. 6(a) and 6(b) that the PALFs obtained using (1 and 3) \% (wt.) $\mathrm{NaOH}$ solution concentrations were still covered by a continuous layer on their surface and the fiber bundles were not visible. It is well known that the continuous layer consists of hemicelluloses, lignin, pectin, waxes and other water soluble compounds that act as cementing substances to bind the fibers together (Asim et al., 2016; Panyasart et al., 2014; Ravindran et al., 2019; Cherian et al., 2010; Kathirselvam et al., 2019). This result therefore signified that the low $\mathrm{NaOH}$ solution concentrations (i.e. 1 and $3 \%$ (wt.)) were unable to effectively remove the cementing substances.

Fig. 6(c) apparently shows that the layer of cementing substances started to disappear at $6 \%$ (wt.) $\mathrm{NaOH}$ solution concentration. At the same concentration, defibrillation also started to occur and the PALF fibrils were visible. Beyond this point, higher $\mathrm{NaOH}$ concentrations (i.e. 10, 15 and $20 \%$ (wt.)) resulted in complete removal of cementing substance layer and higher degree of defibrillation, where the PALF fibril could be observed individually as exhibited in Figs. 6(d), 6(e) and 6(f) (Panyasart et al., 2014; Cherian et al., 2010). It was noteworthy that there was no significant difference between the PALF obtained from the (10, 15 and 20) \% (wt.) $\mathrm{NaOH}$ solution concentrations in terms of degree of defibrillation. Therefore, it could be concluded that $10 \%$ (wt.) of $\mathrm{NaOH}$ solution concentration was the optimum concentration for the chemical extraction method.
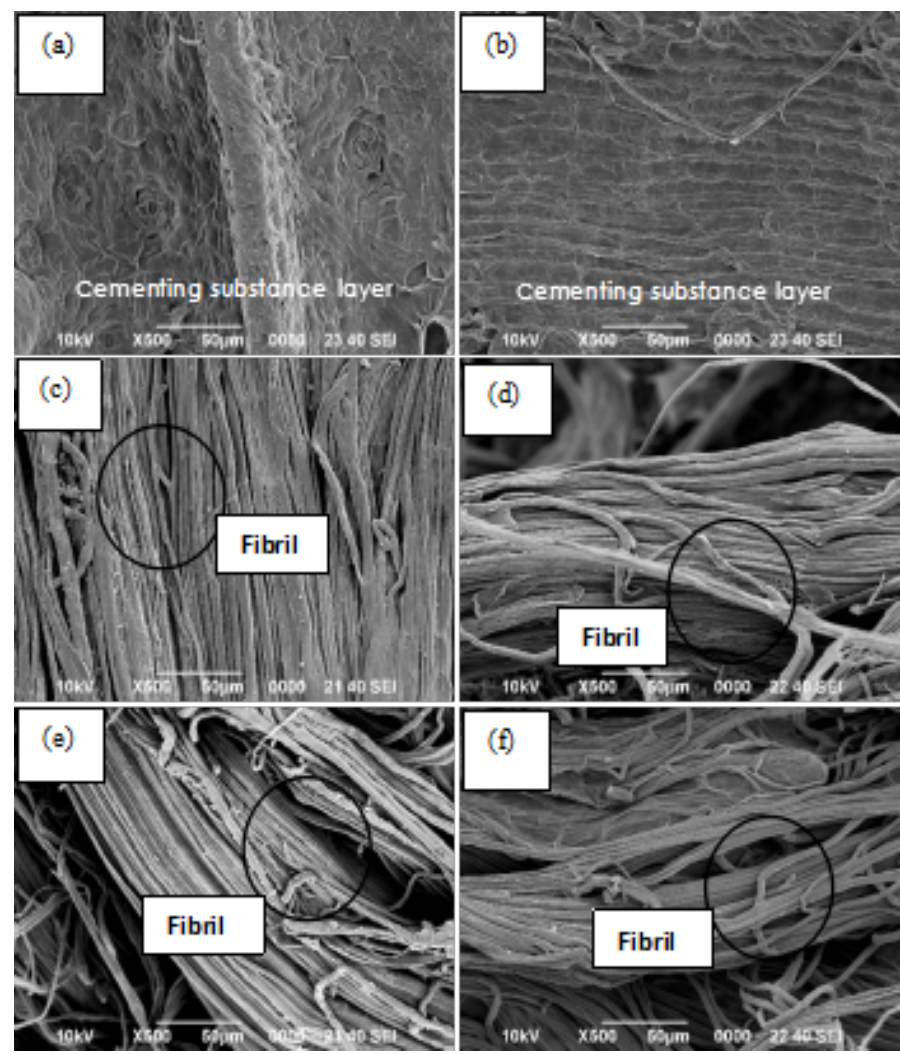

Fig. 6 SEM images (500X magnification) of PALF extracted via chemical extraction using [(a) 1 , (b) 3 , (c) 6 , (d) 10 , (e) 15 , and (f) 20$] \%$ (wt.) $\mathrm{NaOH}$ solution concentrations.

\section{Mechanical-chemical extraction method}

For the mechanical-chemical extraction, the PALs were crushed with a crusher prior to cooking in $\mathrm{NaOH}$ solution at $90{ }^{\circ} \mathrm{C}$. The $\mathrm{NaOH}$ solution concentrations were varied (i.e. 1, 3, 5, 7, 9 and $11 \%$ (wt.)) as previously described in the chemical extraction method. As shown in Fig. 7, a whitish dried pulp was obtained when the concentration of $\mathrm{NaOH}$ solution was set at $3 \%$ (wt.) and above, indicating the complete removal of residues from PALF at these $\mathrm{NaOH}$ solution concentrations. The SEM images of extracted PALF by mechanical-chemical method are presented in Fig. 8. 

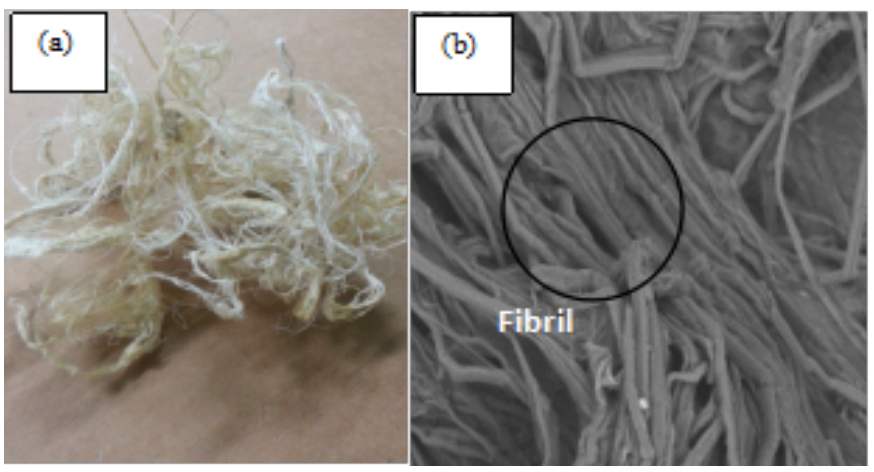

Fig. 7 (a) Visual and (b) SEM (1000X magnification) images of the mechanical-chemical extracted PALF with $3 \%$ (wt.) $\mathrm{NaOH}$ solution concentration was used.
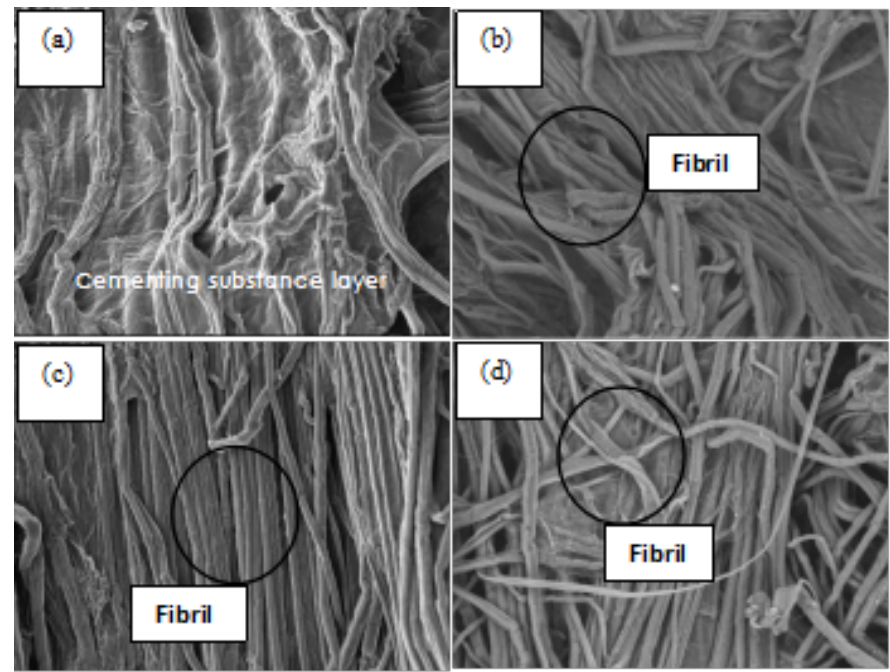

(d)
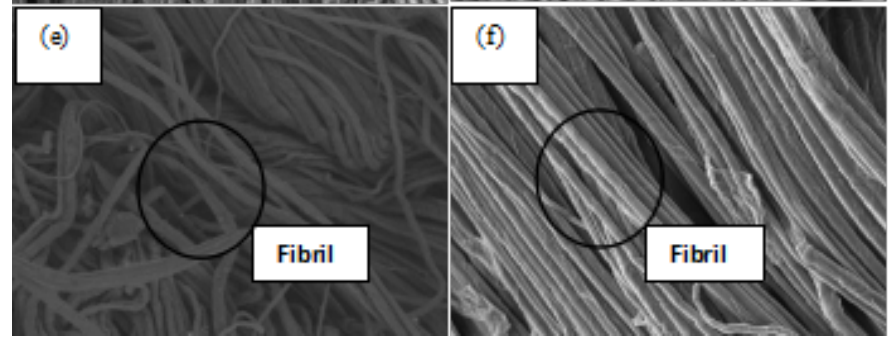

Fig. 8 SEM images (1500X magnification) of PALF extracted via mechanical-chemical extraction using $[(a) 1$, (b) 3 , (c) 5 , (d) 7, (e) 9 , and (f) 11$] \%$ (wt.) $\mathrm{NaOH}$ solution concentrations heated at $90{ }^{\circ} \mathrm{C}$.

From Fig. 8(a), it can be observed that the PALF was still covered with the cementing substance layer. This indicated that it was not sufficient for the defibrillation to occur at $1 \%$ (wt.) $\mathrm{NaOH}$ solution concentration even with the help of heating. The fibril started to appear more prominently at $3 \%$ (wt.) $\mathrm{NaOH}$ solution concentration (Fig. 8(b)). This showed that the mechanical-chemical method, with the help of heating, accelerated the defibrillation process by making it to happen at the lower $\mathrm{NaOH}$ solution concentration as compared to the chemical method. Fig. 8(c) to 8(f) show that there was no significant change between the PALF extracted from (5, 7, 9 and 11) \% (wt.) $\mathrm{NaOH}$ solution concentrations. This implied that with the help of heating at 90 ${ }^{\circ} \mathrm{C}$, for each case, the delignification process was speed up and more fibrils were exposed at and above $3 \%$ (wt.) $\mathrm{NaOH}$ solution concentration.

As presented in Fig. 9, the dry pulp yield decreased with increasing $\mathrm{NaOH}$ solution concentrations. Interestingly, even at $11 \%$ (wt.) $\mathrm{NaOH}$ solution concentration which led to the lowest PALF yield, the quantity of dry pulp obtained was $6.6 \%$ (wt.) which was still significantly higher than that of the chemical extraction $(2.8 \%$ (wt.)). Moreover, a larger quantity of crushed PALF could be treated with the same amount and concentration of the $\mathrm{NaOH}$ solution comparing to the chemical extraction method. This was because by crushing, volume of the PALF decreased and at the same time, surface area of the fibers increased as they were broken down into smaller pieces. The higher surface area also promoted a faster reaction between $\mathrm{NaOH}$ and PAL. Hence, it could be concluded that the mechanical-chemical extraction was the most favourable among all extraction methods. This result was in agreement with the finding by Sarah et al. (2018) who reported that the semimechanical extraction method yielded PALF with high crystallinity and low lignin content.

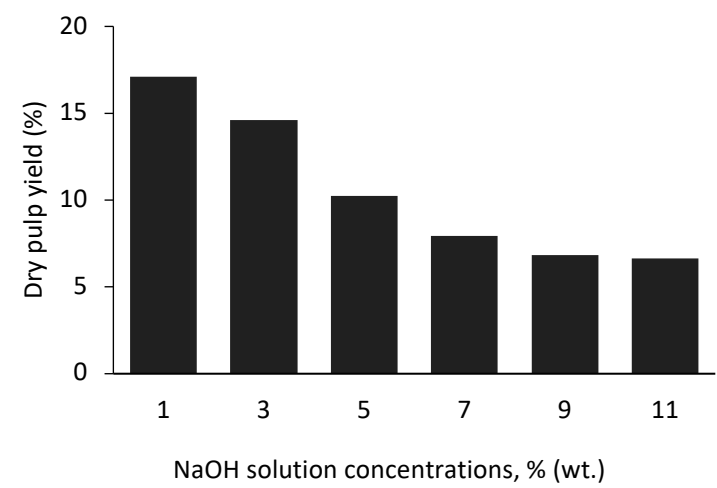

Fig. 9 Effect of $\mathrm{NaOH}$ solution concentrations on the dry pulp yield heated at $90^{\circ} \mathrm{C}$.

After establishing the best extraction method, the effect of cooking time was incorporated to speed up the extraction process. PALFs were extracted at various $\mathrm{NaOH}$ solution concentrations (i.e. 1, 3, 5, 7, 9 and 11) \% (wt.) and subjected to cooking at $90{ }^{\circ} \mathrm{C}$ for $(30,60,90,120$ and 180) min. Again, the solid/liquid ratio of 1:15 was used. The yields of dry pulp at various $\mathrm{NaOH}$ solution concentrations against the cooking time were plotted in Fig. 10. It can be observed that the dry pulp yield decreased with increasing $\mathrm{NaOH}$ solution concentrations observed for every cooking time. This was because the heat could assist $\mathrm{NaOH}$ to break down the glycosidic bond, hence separating the chains of lignincarbohydrates groups to facilitate the lignin removal (Jahan and Pourali, 2019; Ardina et al., 2018). From Fig. 10, it shows that for (1 and 3) $\%$ (wt.) $\mathrm{NaOH}$ solution concentrations, the dry pulp yield decreased as the cooking time increased. However, this trend did not remain for (5 to 11 ) $\%$ (wt.) $\mathrm{NaOH}$ solution concentrations. Thus, $3 \%$ (wt.) $\mathrm{NaOH}$ solution concentration was the limiting concentration that needed to treat the fiber as higher concentration of $\mathrm{NaOH}$ solution gave highly similar yield.

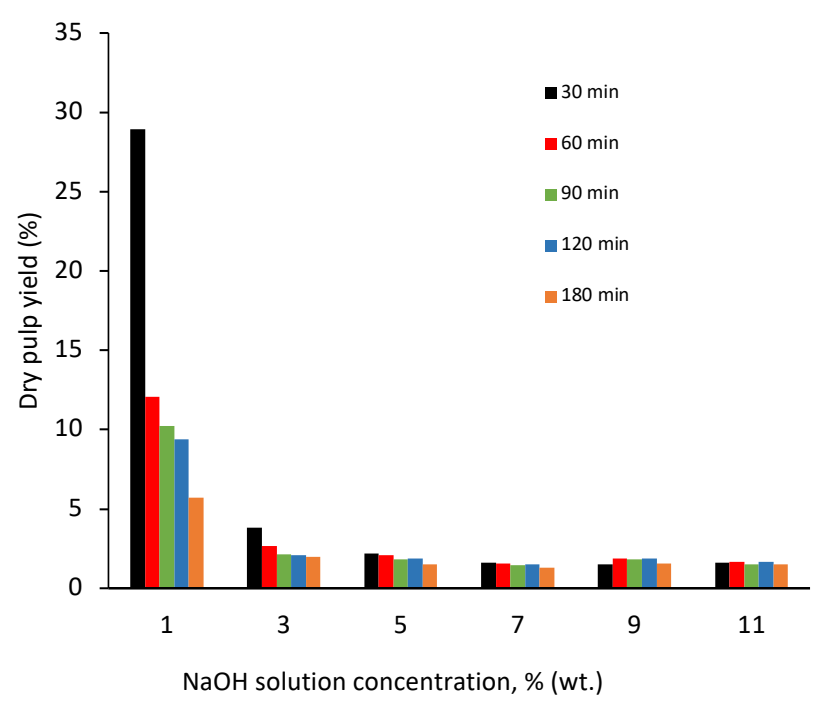

Fig. 10 Effect of cooking time on dry pulp yield over different $\mathrm{NaOH}$ solution concentrations. 
The visual image was used to determine the most suitable cooking time, based on the colour and residues left on PALF cooked at $3 \%$ (wt.) $\mathrm{NaOH}$ solution concentration. From Figs. 11(a) and 11(b), it can be seen the greenish leaf-like residues were still noticeable on the PALF after $30 \mathrm{~min}$ and $60 \mathrm{~min}$ of cooking times. This signified that the cooking time less than 60 min was insufficient to remove the residues. However, above $90 \mathrm{~min}$, all PALFs exhibited whitish coloured dry pulps. Hence, in order to ensure good quality PALFs and save more energy, the optimum cooking time should be at least $90 \mathrm{~min}$.
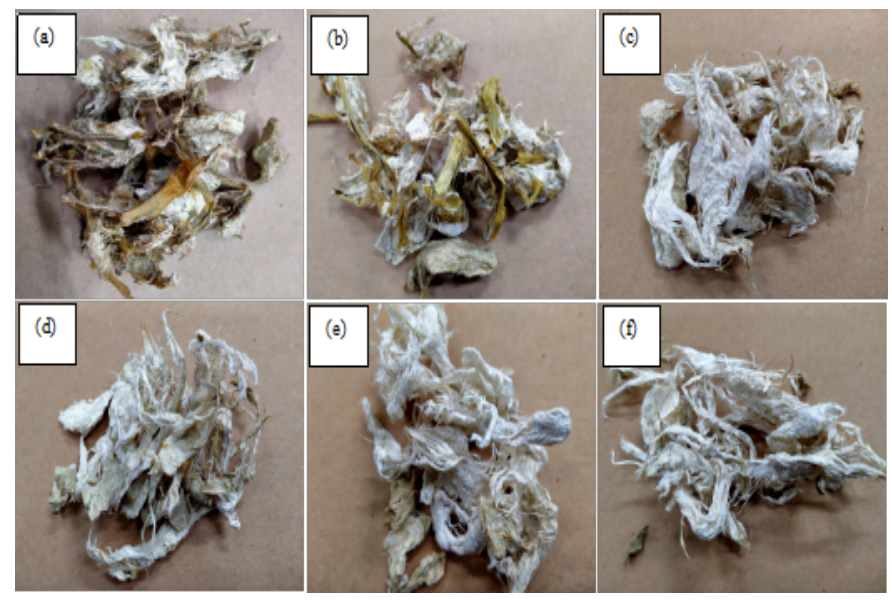

Fig. 11 Visual observation of PALF extracted at $3 \%$ (wt.) $\mathrm{NaOH}$ solution concentration with cooking times of [(a) 30, (b) 60, (c) 90, (d) 120, (e) 150, and (f) 180] $\mathrm{min}$.
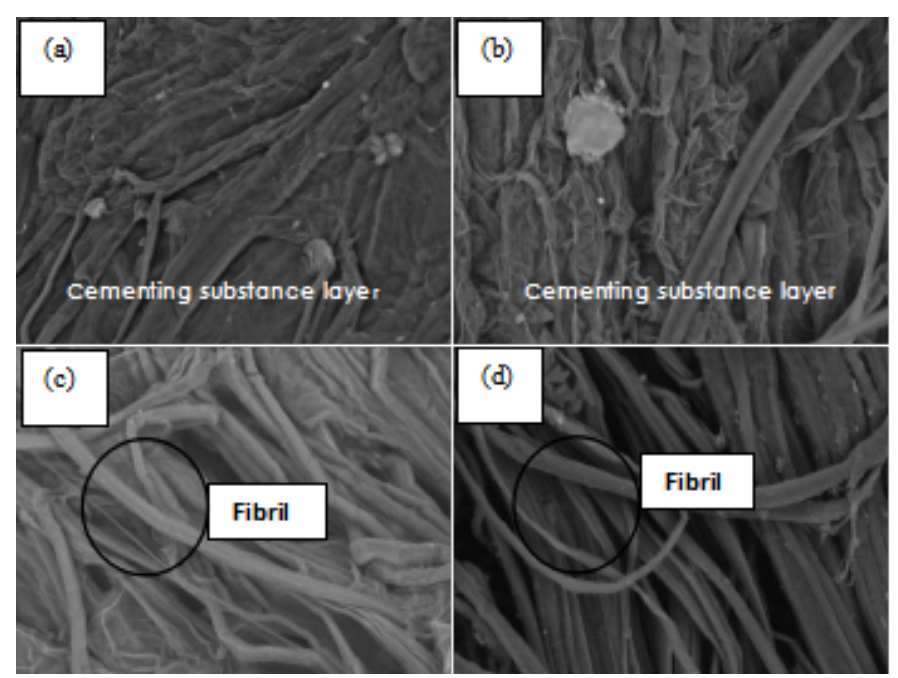

Fig. 12 SEM images (1500X magnification) of PALF extracted with 3 $\%$ (wt.) $\mathrm{NaOH}$ solution concentration heated at $90{ }^{\circ} \mathrm{C}$ for [(a) 30 , (b) 60 , (c) 90, and (d) 120] min.

The SEM images of the PALF obtained at different cooking times are presented in Fig. 12. Figs. 12(a) and 12(b) show that the cementing substance layer was still present if the cooking time was set at $30 \mathrm{~min}$ and $60 \mathrm{~min}$. This indicated that at $3 \%$ (wt.) $\mathrm{NaOH}$ solution concentration, $30 \mathrm{~min}$ and $60 \mathrm{~min}$. cooking times were not sufficient for the complete removal of cementing substance layer and defibrillation. On a contrary, the defibrillation occurred at longer heating times of 90 and $120 \mathrm{~min}$ (Figs. 12(c) and 12(d)). As cooking times that were longer than necessary could lead to waste of energy, thus it was concluded that $90 \mathrm{~min}$ as the optimum cooking time for the process.

\section{CONCLUSIONS}

The pineapple leave fiber (PALF) was successfully extracted through the mechanical, chemical and mechanical-chemical extraction methods. Based on the dry pulp yield and morphological appearance, the manual retting using a ceramic scrapper was the most inefficient method since it was highly labour intensive and yet, produced the lowest dry pulp yield at about $1.8 \%$ (wt.). The water retting for $21 \mathrm{~d}$ led to about $6.0 \%$ (wt.) dry pulp yields. However, the pulps were dark greenish in colour, indicating the presence of unwanted residues, as verified by SEM image. The chemical extraction of PALF using (6 to 20) \% (wt.) $\mathrm{NaOH}$ solution concentrations was found to successfully extract good quality PALF, as lower $\mathrm{NaOH}$ solution concentrations of $1 \%$ (wt.) and $3 \%$ (wt.) failed to completely remove the residues. As compared to the chemical extraction, the mechanical-chemical extraction promised a dry pulp yield of more than $6.0 \%$ (wt.) even at higher $\mathrm{NaOH}$ solution concentrations. Moreover, the same given amount and concentration of $\mathrm{NaOH}$ solution was able to treat a larger quantity of crushed PAL. It was also found that the extraction process could speed up by cooking the solution at $90{ }^{\circ} \mathrm{C}$ for $90 \mathrm{~min}$. The cooking time lesser than 90 min resulted in leaf-like PALF, which is an indication that the leaf structure was not properly broken down. Finally, it could be concluded that the mechanical-chemical method using $3 \%$ (wt.) $\mathrm{NaOH}$ solution concentration, solid/liquid ratio of $1: 15$ and 90 min cooking time was the best method to extract the PALF from the PAL.

\section{ACKNOWLEDGEMENTS}

The authors would wish to express their gratitude to Universiti Teknologi Malaysia and Biopolymer Research Group for the laboratory facilities and technical support. The authors would also wish to thank Malaysia Ministry of Education (MoE) for providing financial support via Fundamental Research Grant Scheme (FRGS), R.J130000.7851.5F203.

\section{REFERENCES}

Ardina, V., Irawan, B., Prajitno, D. H., and Roesyadi, A. 2018. Active alkali charge effect on kraft pulping process of acacia mangium and eucalyptus pellita in AIP Conf. Proc.. 2014, 9-15.

Arib, R. M. N., Sapuan, S. M., Ahmad, M. M. H. M., Paridah, M. T. and Khairul Zaman, H. M. D. 2006. Mechanical properties of pineapple leaf fibre reinforced polypropylene composites. Mater. Des. 27, 391-396.

Asim, M., Jawaid, M., Abdan, K., and Ishak, M. R. 2016. Effect of alkali and silane treatments on mechanical and fibre-matrix bond strength of kenaf and pineapple leaf fibres. J. Bionic Eng. 13, 426-435.

Asim, M., Paridah, M. T., Saba, N., Jawaid, M., Alothman, O. Y., Nasir, M. and Almutairi, Z. 2018. Thermal, physical properties and flammability of silane treated kenaf/pineapple leaf fibres phenolic hybrid composites. Compos. Struct. 202, 1330-1338.

Beckline, M., Yujun, S., Eric, Z., and Kato, M. S. 2016. Paper consumption and environmental impact in an emerging economy. J. Energy, Environ. Chem. Eng. 1, 1, 13-18.

Cherian, B. M., Leão, A. L., de Souza S. F., Thomas, S., Pothan, L. A., and Kottaisamy, M. 2010. Isolation of nanocellulose from pineapple leaf fibres by steam explosion. Carbohydr. Polym. 81, 720-725.

Daud, Z., Mohd Hatta, M. Z., Mohd Kassim, A. S., and Mohd, A. A. 2013. Suitability of Malaysia's pineapple leaf and napier grass as a fiber substitution for paper making industry in EnCon 2013, 6th Engineering Conference. Energy Environ. 7, 1-4.

FAO, 2014. Pulp and paper capacities survey 2013-2018. Rome.

Feng, Z. and Alén, R. 2001. Soda-AQ pulping of reed canary grass. Ind. Crops Prod. 14, 1, 31-39.

Ferreira, A. C. H., Rodriguez, N. M., Neiva, J. N. M., Pimentel, P. G., Gomes, S. P., Campos, W. E., Lopes, F. C. F., Mizubuti, I. Y., Moreira, G. R. 2019. In situ degradability of elephant grass ensiled with acerola by-product. Semin. Agrar. 40, 5, 2427-2438.

Haameem, M., Abdul Majid, M. S., Afendi, M., Marzuki, H. F. A., Fahmi, I., and Gibson, A. G. 2016. Mechanical properties of napier grass fibre/polyester composites. Compos. Struct. 136, 1-10.

Hedjazi, S., Kordsachia, O., Patt, R., Latibari, A. J., and Tschirner, U. 2009 Alkaline sulfite-anthraquinone (AS/AQ) pulping of wheat straw and totally chlorine free (TCF) bleaching of pulps. Ind. Crops Prod. 29, 1, 27-36.

Jahan, L., A. and Pourali, K. 2019. Effect of alkaline pre-hydrolysis on soda pulping of wheat straw. Cellul. Chem. Technol. 53, 1-2, 79-85.

Kathirselvam, M., Kumaravel, A., Arthanarieswaran, V. P., and Saravanakumar, S. S. 2019. Characterization of cellulose fibers in thespesia populnea barks: Influence of alkali treatment. Carbohydr. Polym. 217, 178-189. 
Kim, S., Park, J. M., Seo, J. W., and Kim, C. H. 2012. Sequential acid-/alkalipretreatment of empty palm fruit bunch fiber. Bioresour. Technol. 109, 229233.

Laftah, W. A. and Abdul Rahaman, W. A. W. 2015. Chemical pulping of waste pineapple leaves fiber for kraft paper production. J. Mater. Res. Technol. 4 , 3, 254-261.

Lai, J. C., Rahman, W. A. W. A., and Toh, W. Y. 2013. Characterisation of sago pith waste and its composites. Ind. Crops Prod. 45, 319-326.

Low, J. H., Ghanbari, T., Rahman, W. A. W. A. and Majid, R. A. 2018.

Preparation and characterization of kenaf papers reinforced with tapioca starch:physicomechanical and morphological properties. J. Nat. Fibers. 15, 2, 191-203.

Low, J. H., Xun, L. Z., Yoon, L. W., Pang, M. M. and Wong, S. 2019. Exploration of tree pruning waste for papermaking. AIP Conf. Proc. 2137 020008.

Majid, R. A., Mohamad, Z., Rusman, R., Zulkornain, A. A., Halim, N. A., Abdullah, M., Low, J. H. 2018. Development of tea waste/kapok fiber composite paper. Chem. Eng. Trans. 63, 457-462.

Mohamed, A. R., Sapuan, S. M., Shahjahan, M., and Khalina, A. 2009. Characterization of pineapple leaf fibers from selected Malaysian cultivars. J. Food, Agric. Environ. 7, 1, 235-240.

Panyasart, K., Chaiyut, N., Amornsakchai, T., and Santawitee, O. 2014. Effect of surface treatment on the properties of pineapple leaf fibers reinforced polyamide 6 composites. Energy Procedia. 56, 406 - 413.

Putra, A., Or, K. H., Selamat, M. Z., Mohd Nor, M. J., Hassan, M. H. and Prasetiyo, I. 2018. Sound absorption of extracted pineapple-leaf fibres. Appl. Acoust. 136, 9-15.

Ravindran, L., Sreekala, M. S., and Thomas, S. 2019. Novel processing parameters for the extraction of cellulose nanofibers (CNF) from environmentally benign pineapple leaf fibres (PALF): Structure-property relationships. Int. J. Biol. Macromol. 131, 858-870.

Rezayati-Charani, P., Mohammadi-Rovshandeh, J., Hashemi, S. J. and KazemiNajafi, S. 2006. Influence of dimethyl formamide pulping of bagasse on pulp properties. Bioresour. Technol. 97, 18, 2435-2442.
Ridzuan, M. J. M., Abdul Majid, M. S., Khasrib, A., Gan, E. H. D., Razlan, Z. M. and Syahrullail, S. 2019. Effect of pineapple leaf (PALF), napier, and hemp fibres as filler on the scratch resistance of epoxy composites. J. Mater. Res. Technol. 8, 6, 5384-5395.

Rodríguez, A., Serrano, L., Moral, A., Pérez, A., and Jiménez, L. 2008. Use of high-boiling point organic solvents for pulping oil palm empty fruit bunches. Bioresour. Technol. 99, 6, 1743-1749.

Rodríguez, A., Serrano, L., Moral, A., and Jiménez, L. 2008. Pulping of rice straw with high-boiling point organosolv solvents. Biochem. Eng. J. 42, 3, 243-247.

Saad, M. B. W., Oliveira, L. R. M., Cândido, R. G., Quintana, G., Rocha, G. J. M., and Gonçalves, A. R. 2008. Preliminary studies on fungal treatment of sugarcane straw for organosolv pulping. Enzyme Microb. Technol. 43, 2, 220-225.

Sarah, S., Rahman, W. A. W. A., Majid, R. A., Yahya, W. J., Adrus, N., Hasannuddin, A. K. and Low, J. H. 2018. Optimization of pineapple leaf fibre extraction methods and their biodegradabilities for soil cover application. J. Polym. Environ. 26, 1, 319-32.

Senthilkumar, K., Saba, N., Chandrasekar, M., Jawaid, M., Rajini, N., Alothman, O. Y. and Siengchin, S. 2019. Evaluation of mechanical and free vibration properties of the pineapple leaf fibre reinforced polyester composites. Constr. Build Mater. 195, 423-432.

Sibaly, S. and Jeetah, P. 2017. Production of paper from pineapple leaves. $J$. Environ. Chem. Eng. 5, 5978-5986.

Wang, J., Deng, Y., Qian, Y., Qiu, X., Ren, Y., and Yang, D. 2016. Reduction of lignin color via one-step UV irradiation. Green Chem. 18, 3, 695-699.

Yusof, Y., Ahmad, A. R., Wahab, M. S., Mustapa, M. S. and Tahar, M. S. 2012. Producing paper using pineapple leaf fiber. Adv. Mater. Res. 383-390, 33823386.

Zin, M. H., Abdan, K., Mazlan, N., Zainuddin, E. S., Liew, K. E. and Norizan, M. N. 2019. Automated spray up process for pineapple leaf fibre hybrid biocomposites. Compos. B. 177, 107306. 